Journal of Env. Engineering \& Waste Management, Vol. 3, No. 1, April 2018: 13-20

\title{
POTENSI GAMAL (Gliricidia sepium) SEBAGAI BAHAN BAKU PEMBANGKIT LISTRIK TENAGA BIOMASSA STUDI KASUS : KABUPATEN MANGGARAI TIMUR (NTT)
}

\section{The Potential of Gamal (Gliricidia sepium) as Raw Material for Biomass Power Plans (Case Study : East Manggarai District - East Nusa Tenggara Province)}

\author{
Dedi Hudaedi ${ }^{1}$ Hariyadi $^{2}$ dan Syaiful Anwar ${ }^{3}$ \\ Program Studi Pengelolaan Sumberdaya Lingkungan \\ Institut Pertanian Bogor Kampus IPB Baranangsiang, \\ Jln. Raya Pajajaran, Bogor 16144
}

ddhudaedi@gmail.com¹, hariyadiipb@rocketmail.com², syaianwar@yahoo.com

\begin{abstract}
Abstrak: Kemampuan Kabupaten Manggarai Timur untuk memenuhi kebutuhan energi listrik daerah cukup rendah, diperkirakan hanya 44,91\%. Hal ini disebabkan oleh kondisi alam yang memiliki iklim kering dan lahan kritis, sehingga sulit untuk dapat memperbaiki ekonomi masyarakat dan daerah secara umum untuk pengembangan listrik yang memadai. Oleh karena itu, kebutuhan energi listrik telah menjadi tantangan pembangunan, sementara energi fosil tidak dapat dipertahankan. Penyediaan listrik perlu dilakukan melalui diversifikasi energi alternatif. Pembangunan pembangkit listrik tenaga biomassa dari tanaman Gamal (Gliricidia sepium) merupakan potensi alternatif yang bisa dikembangkan. Penelitian ini bertujuan untuk mengidentifikasi potensi lahan Gamal dan memprediksi potensi listrik. Metode yang digunakan adalah analisis Citra TM 8 dengan menggunakan GIS Version 10.1 sebagai alat analisis. Pengumpulan data melalui wawancara masyarakat dengan metode purposive sampling. Hasil penelitian ini menggambarkan lahan terdegradasi seluas 187.462.01 hektar yang merupakan lahan potensial untuk penanaman Gamal. Prediksi lahan yang terdegradasi dapat menghasilkan 98 181,76 m3 produk kayu dan menghasilkan listrik 18,90 MW / tahun.
\end{abstract}

Kata Kunci: energi listrik, lahan kritis, Gliricidia sepium, pembangkit listrik

Abstract: The ability of East Manggarai Regency to meet the electricity needs of the region is estimated at only 44.91\%. This metter is caused by natural conditions that have a dry climate and critical land, making it difficult to can improve of community economy and generaly region for development of adequate electricity. Therefore, the electrical energi need has been to development challenge, while fossil energi untenable. The construction of a biomass from the Gamal (Gliricidia sepium) plant is a potential alternative to develop. This research aimed to identify the potential lands for Gamal and predict the electricity potency. The method was image analysis from Citra TM 8 using GIS Version 10.1 as an analysis tool. Collecting data was through community interviews with purposive sampling method. The results of this study described the degraded land areas of 187.462,01 hectares which are the potential land for Gamal planting. Prediction of critical lands could produce $98181.76 \mathrm{~m}^{3}$ of wood products and generate $18.90 \mathrm{MW} /$ year of electricity.

Keywords:, electricity, degraded lands, Gliricidia sepium, power plant

\section{PENDAHULUAN}

Ketersediaan listrik nasional tahun 2015 diperkirakan sebesar 233.981,98 GWh (BPPT, 2016). Namun jumlah tersebut belum mampu untuk memenuhi semua wilayah di Indonesia (BP-PEN, 2006; Perpres, 2017).

Berdasarkan perbandingan jumlah penduduk dan penduduk yang mendapatkan listrik atau rasio elektrifikasi nasional tahun 2015 hanya sebesar 88,30\%. Rasio elektrifikasi tertinggi adalah DKI Jakarta sebesar 99,76\%, sedangkan Provinsi Papua dan Nusa Tenggara Timur menjadi wilayah dengan rasio terendah, yakni masing-masing sebesar 48,3 dan 59,2 persen. Rasio eletrifikasi di
Kabupaten Manggarai Timur 44,91\% yang berarti hanya lebih kurang setengah dari rumah total seluruh rumah berpenghuni yang memiliki listrik. Jika dibandingkan dengan rasio desa berlistrik hanya $22,22 \%$ atau 32 dari 144 desa (ESDM, 2015; PLN, 2016; 2017).

Nusa Tenggara Timur termasuk pada daerah dengan tipe iklim kering (Pasaribu, 2007; Lassa, et al. 2014) dan kondisi lahan kritis (Njurumana et al. 2008) serta saat ini merupakan provinsi yang tidak memiliki potensi energi selain dari diesel, yang 
berdasarkan kajian ekonomi regional mengakibatkan biaya ekonomi tinggi (BI, 2009; Wolo dan Winahju, 2009; Rachmawan, 2014).

Penyediaan tenaga listrik perlu dilakukan melalui diversifikasi sumber energi alternatif seperi matahari, angin, air, gelombang laut, biomassa, panas bumi dan bahan bakar nabati (biofuel) (Hargiardana, 2013; BPPT, 2016).

Pemerintah melalui Peraturan Menteri Energi dan Sumberdaya Mineral Nomor 38 Tahun 2016 menetapkan kebijakan tentang penyediaan tenaga listrik untuk skala kecil (Ahmad 2016), guna memenuhi kebutuhan listrik di pedesaan yang belum berkembang, pedesaan terpencil, pedesaan perbatasan dan pulau kecil berpenduduk dengan mengoptimalkan sumber energi baru dan terbarukan wilayah setempat (DESDM, 2006; ESDM, 2015; Perpres, 2017).

Sesuai kondisi biofisik alami Nusa Tenggara Timur yang kering dan lahan kritis, tanaman Gamal (Gliricidia sepium) merupakan tanaman pilihan yang dapat dikembangkan. Tanaman Gamal (Gliricidia sepium) merupakan tanaman pioneer yang dapat tumbuh pada kondisi iklim ekstrim (Elevitch dan Francis, 2005). Biomass dari tanaman sebagai sumber energi listrik memiliki nilai ekonomi yang lebih baik. (German et all. 2010)

Sebagai salah satu sumber pengembangan energi biomassa tanaman Gamal (Gliricidia sepium) memiliki keunggulan energi bersih yang baru dan terbarukan, berkesinambungan, dan relatif ramah lingkungan dengan keuntungan lainya limbah abu sisa pembakaran biomassa jumlah lebih sedikit (Cahyono, et al. 2008). Energi biomassa sebagai sumber daya energi akan lebih kecil mengalami fluktuasi harga dunia atau ketidakpastian pasokan sebagai bahan bakar impor dan salah satu cara untuk mencegah lebih banyak produksi karbon dioksida $\left(\mathrm{CO}_{2}\right)$ di atmosfer (McKendry, 2002).

Kebutuhan energi listrik di Kabupaten Nusa Tenggara Timur menjadi fokus pemerintah untuk meningkatkan dan menggerakkan ekonomi masyarakat.
Rencana pembangunan pembangkit listrik tenaga biomassa yang akan dikembangkan Pemerintah Daerah Kabupaten Manggarai Timur berkapasitas 1 MW pada tahap I dan 10 MW pada tahap II. Energi alternatif dengan pengembangan sumber energi biomassa merupakan potensi yang dapat dikembangkan (Price, 1998). Tujuan penelitian adalah mengidentifikasi potensi tanaman Gamal (Gliricidia sepium) untuk kapasitas pembangkit $10 \mathrm{MW}$ dan potensi luasan lahan kritis untuk pembangunan pembangkit listrik tenaga biomassa di Kabupaten Manggarai Timur.

\section{METODE PENELITIAN}

Saat ini lagi dipersiapkan Pembangkit Listrik Tenaga Biomassa di Desa Gunung Kecamatan Kota Komba Kabupaten Manggarai Timur dan sudah dilakukan penanaman gamal pada lahan seluas 2.090 hektar untuk kapasitas pembangkit 1 MW yang oleh Kabupaten Manggarai Timur bekerja sama dengan Energy Lestari Foundation (ELF) dan perlu pengembangan untuk kapasitas pembangkit $10 \mathrm{MW}$. Waktu penelitian dilaksanakan selama enam bulan pada Nopember 2016 sampai Maret 2017.

\section{Bahan dan Alat}

Alat yang digunakan dalam pengolahan data adalah antara lain: ArcGIS 10.1. sebagai tool analisis, GPS, kompas, haga-hypsometer, phi-band dan alat-alat tulis. Bahan meliputi, yaitu: Ppta RBI skala 1:250.000, citra SRTM 90m (sumber USGS 2000), peta curah hujan, peta peta kawasan hutan.

\section{Analisis Data}

\section{Prediksi Lahan Potensial}

Analisis potensi hahan untuk pengembangan Gamal (Gliricidia sepium) difokuskan pada lahan kritis dengan parameter tingkat kekritisan lahan mengacu pada SK Dirjen RRL No. 041/Kpts/V/1998. Analisis lahan kritis dilakukan dengan digitasi tutupan (cover land area) dari berbagai sumber peta diatas, dengan menggunakan tool aplikasi ArcGis 10.1. 


\section{Prediksi Potensi Supplay Bahan Baku}

Perhitungan potensi volume Gamal (Gliricidia sepium) dalam meter kubik per hektar adalah berdasarkan jarak tanam sesuai tingkat kritis lahan menurut Peraturan Menteri Kehutanan Nomor P.65/MenhutII/2014, yakni pada lahan sangat kritis jarak tanam 1 x 1 meter, lahan kritis $3 \times 3$ meter, lahan agak kritis $3 \times 6$ meter, dan pada lahan potensial kritis $6 \times 6$ meter dengan riap tumbuh $0,0011 \mathrm{~m}^{3} /$ th dan nilai kalor $4,9 \mathrm{Kkal}$ (Elevitch dan Francis, 2005). Jumlah pohon per hektar pada masing-masing tingkat kritis dijabarkan sebagaimana terlihat pada Tabel 1.

Tabe 1. Jarak tanam pada tingkat kritis lahan

\begin{tabular}{lcc}
\hline Sangat Kritis & Jarak Tanam & $\begin{array}{c}\text { Jumlah Per } \\
\text { hektar (Batang) }\end{array}$ \\
\hline Sangat Kritis & 1 X 1 & 10000 \\
Kritis & 1 X 1 & 10000 \\
Agak Kritis & 3 X 3 & 1.111 \\
Tidak Kritis & 3 X 6 & 555 \\
\hline
\end{tabular}

Sumber: Permenhut Nomor: P.65/Menhut-II/2014

\section{Potensi Per hektar}

Untuk mengetahui potensi per hektar persamaan rumus volume yang digunakan sebagaimana yang digunakan Roliadi et all. (2010) sebagai berikut:

$$
\mathrm{V}=\text { Lbds } \mathrm{x} T
$$

Keterangan:

Lbds = Luas bidang dasar

$\mathrm{T} \quad=$ Tinggi rata-rata 2 meter siap tebang

Lbds pada kayu Gamal dapat diubah dengan riap tumbuh rata-rata sebesar $0.0011 \mathrm{~m} 3$ per tahun (Elevitch dan Francis, 2005), sehingga persamaan rumus yang digunakan adalah:

$$
\begin{array}{ll}
\mathrm{V} & =0.0011 \times \mathrm{U} \times \mathrm{T} \\
\mathrm{V} / \mathrm{Ha} & =\mathrm{V} \times \mathrm{JB} / \mathrm{Ha}
\end{array}
$$

Keterangan:

$$
\begin{aligned}
& 0.0011=\text { Riap tumbuh Gamal per tahun } \\
& \mathrm{U}=\text { Umur pohon } \\
& \mathrm{T}=\text { Tinggi rata-rata (2 meter) } \\
& \mathrm{JB} / \mathrm{Ha}=\text { Jumlah Batang per Hektar } \\
& \mathrm{V} / \mathrm{Ha}=\text { Volume perhektar }
\end{aligned}
$$

\section{Potensi Per Kriteria Lahan Kritis}

Perhitugan potensi pada kriteria lahan kritis merupakan perkalian luas lahan kritis sesuai kriteria dengan jumlah pohon per hektar. Luas lahan kritis pada masing masing kriteria diperoleh dari hasil analisis citra TM 8 menggunakan ArcGIS 10.1. Sehingga dapat dibuat rumus persamaan sebagai berikut:

$$
\begin{array}{rll}
\text { Vsk } & =\text { Lsk } x & \mathrm{JB} / \mathrm{Ha} \\
\mathrm{Vk} & =\mathrm{Lk} \times \mathrm{JB} / \mathrm{Ha} \\
\mathrm{Vak} & =\mathrm{Lak} \times & \mathrm{JB} / \mathrm{Ha} \\
\mathrm{Vtk} & =\mathrm{Ltk} \times & \mathrm{JB} / \mathrm{Ha}
\end{array}
$$

\section{Keteragan:}

Vsk $=$ Volume lahan sangat kritis (Lsk)

$\mathrm{Vk}=$ Volume lahan Kritis (Lk)

Vak = Volume lahan agak kritis (Lak)

Vtk = Volume lahan tidak kritis (Ltk)

\section{Perhitungan Potensi Total}

Hasil perhitungan potensi per hektar pada masing-masing kriteria lahan kritis, maka perhitungan potensi total kayu dari hasil Penanaman Gamal (Gliricidia sepium) dapat dihitung dengan persamaan rumus sebagai berikut:

$$
V_{P}=V_{t} x F E
$$

Keterangan :

$V_{p} \quad=$ Volume kayu potensial

$V_{t}=$ Volume total lahan kritis

$F E=$ Faktor eksploitasi $(96,5 \%)$ dengan menggunakan faktor eksploitasi pada hutan tanaman industri (HTI)

\section{Analisis Prediksi Potensi Produksi Energi}

Hasil perhitungan potensi kayu Gamal (Gliricidia sepium) bahan baku potensi energi dihitung dengan kadar air standar sebesar $56 \%$ dengan menggunakan persamaan rumus sebagai berikut:

$$
V_{b}=V_{p}-\left(V_{p} x K A\right)
$$

Keterangan :

$V_{b}=$ volume kayu setelah volume dikalikan KA

$V_{p} \quad=$ Volume kayu potensial 
$K A=$ kadar air kayu Gamal sebesar 0,56 $(56 \%)$

Suplai bahan baku ditetapkan berdasarkan perhitungan dalam ton dengan konversi dari $\mathrm{m}^{3}$ ke dalam ton yang menggunakan rumus standar sebagaimana persamaan rumus :

$$
V_{e}=V_{b} x A K
$$

Keterangan :

$V_{e}=$ volume kayu dikonversi ke ton (ton/ha/th

$V_{b}=$ volume kayu setelah volume dikalikan KA

$A K=$ angka konversi meter kubik $\left(\mathrm{m}^{3}\right) \mathrm{ke}$ ton $(0,95)$

Berdasarkan rangkaian rumus di atas, potensi energi yang dihasilkan oleh Gamal (Gliricidia sepium) sebagai bahan baku energi dapat diketahui dengan rumus sebagaimana persamaan:

$$
W_{e}=\frac{V_{e}}{K_{t}}
$$

Keterangan:

$$
\begin{aligned}
W_{e}= & \begin{array}{l}
\text { suplai energi listrik/ha/th } \\
(\mathrm{kWh} / \mathrm{ha} / \mathrm{th})
\end{array} \\
V_{e}= & \begin{array}{l}
\text { volume kayu dikonversi ke ton } \\
(\text { ton/ha/th) }
\end{array} \\
K_{t}= & \begin{array}{l}
\text { angka konversi } 1 \text { ton sebesar } 4,9 \\
\text { kilo kalori (kkal) }
\end{array}
\end{aligned}
$$

\section{HASIL DAN PEMBAHASAN Identifikasi Potensi Lahan}

Hasil analisis penutupan lahan menunjukan bahwa tutupan berupa semak belukar merupakan tutupan terluas $111.839,00$ ha $(46,50)$ dan tutupan lahan terkecil berupa tanah terbuka 93,00 ha $(0,04 \%)$ dan tubuh air 73 ha $(0,03)$. Tutupan lahan berupa hutan mencakup 62.651 hektar sedangkan berdasarkan data statistik Kabupaten Manggarai Timur Tahun 2015 luas kawasan hutan 90.020 hektar yang dikelompokan kedalam fungsi hutan, yakni: Hutan Produksi (HP) seluas 4.954 hektar, Hutan Produksi Terbatas (HPT) seluas 31.546 hektar, Hutan Produksi Konversi (HPK) seluas 5.705 hektar, Hutan Lindung (HL) seluas 15.567 hektar dan Taman Wisata Alam (TWA) seluas 32.249 hektar, sebagaimana terlihat pada Tabel 2.

Tabel 2. Klasifikasi dan luas penutupan lahan Kabupaten Manggarai Timur

\begin{tabular}{lrr}
\hline Klasifikasi Penutupan Lahan & Luas (ha) & $\%$ \\
\hline Belukar rawa & 955,00 & 0,40 \\
Hutan lahan hutan primer & $25.751,00$ & 10,71 \\
Hutan lahan hutan sekunder & $36.860,00$ & 15,34 \\
Pemukiman & 884,00 & 0,37 \\
Pertanian lahan kering & $5.252,00$ & 2,18 \\
Pertanian lahan kering dan semak & $22.113,00$ & 9,19 \\
Savana & $34.924,00$ & 14,52 \\
Sawah & $1.708,00$ & 0,71 \\
Semak belukar & $111.839,00$ & 46,50 \\
Tanah terbuka & 93,00 & 0,04 \\
Tubuh air & 73,00 & 0,03 \\
\hline Jumlah & 240492,00 & 100,00 \\
\hline
\end{tabular}

Sumber: Diolah dari data primer (2017)

Hasil analisis kriteria lahan kritis di Kabupaten Manggarai Timur adalah Sangat Kritis (Sk) 1.887 (1,01\%), Kritis (k) seluas 117.571 hektar $(62,72)$ dan sisanya adalah agak kritis (ak) seluas 42.627 hektar
$(22,74 \%)$ dan tidak kritis (tk) seluas 25.376 hektar $(13,54 \%)$. Tutupan lahan dan kondisi lahan kritis sebagaimana terlihat pada Tabel 3. Tampilan tutupan lahan dan kritis sebagaimana terlihat pada Gambar 1. 
Tabel 3. Luas lahan kritis

\begin{tabular}{|c|c|c|c|c|c|}
\hline \multirow{2}{*}{ Kecamatan } & \multicolumn{4}{|c|}{ Kategori Tingkat Kekritisan Lahan } & \multirow{2}{*}{ Total (ha) } \\
\hline & Tidak Kritis (ha) & Agak Kritis (ha) & Kritis (ha) & Sangat Kritis (ha) & \\
\hline Borong & 3.744 & 5.344 & 8.540 & 133 & 17.762 \\
\hline Rana Mese & 757 & - & - & - & 757 \\
\hline Kota Komba & - & - & 9.988 & 210 & 10.198 \\
\hline Elar & 902 & 1.072 & 2.059 & 32 & 4.065 \\
\hline Elar Selatan & 1.224 & 1.453 & 2.791 & - & 5.468 \\
\hline Sambi Rampas & 14.641 & 17.383 & 33.395 & 564 & 65.983 \\
\hline Poco Ranaka & - & 3.324 & 19.271 & - & 22.595 \\
\hline Poco Ranaka Timur & - & 3.748 & 21.733 & 639 & 26.121 \\
\hline Lamba Leda & 4.109 & 10.303 & 19.794 & 309 & 34.514 \\
\hline Total & 25.376 & 42.627 & 117.571 & 1.887 & 187.463 \\
\hline
\end{tabular}

Sumber: Diolah dari data primer (2017)

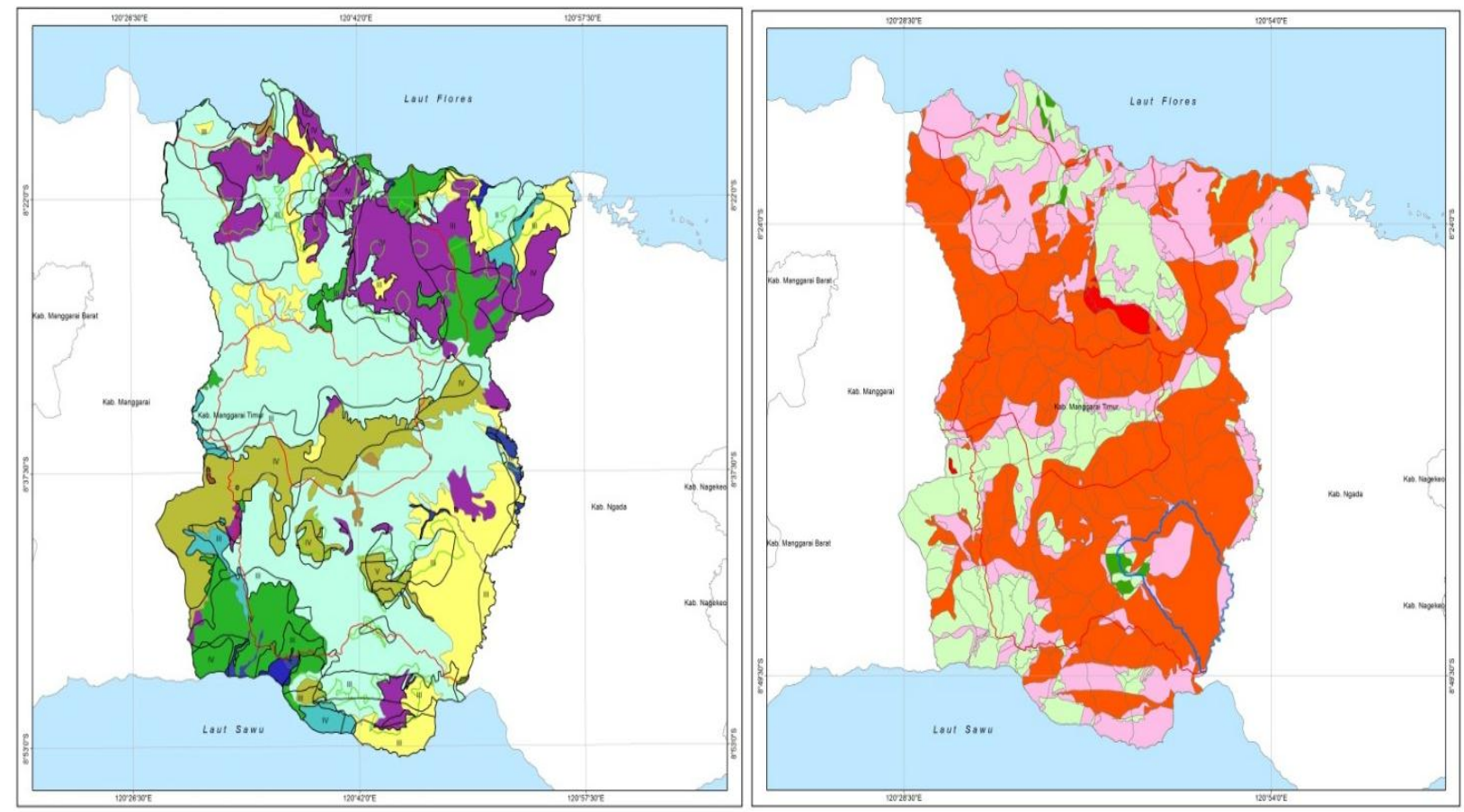

Gambar 1. Tutupan lahan dan kondisi lahan kritis

Identifikasi potensi lahan pengembangan tanaman Gamal (Gliricidia sepium) di lakukan terhadap lahan kritis karena gamal merupakan tumbuhan pionir yang dapat ber adaptasi pada iklim kering dan kondisi lahan kritis, termasuk tanah yang kurang subur, tanah asam dan tanah tererosi. Hasil pengamatan di lapangan pola penanaman Gamal (Gliricidia sepium) dilakukan pada lokasi yang akan dilakukan pada lahan kondisi semak belukar. Tanaman Gamal (Gliricidia sepium) akan mampu untuk mematikan alang-alang dan menyuburkan tanah setelah kondisi alang-alang mati. Hal tersebut sebagaimana wawancara dengan masyarakat yang mengatakan tanaman Gamal (Gliricidia sepium) mampu untuk mematikan alang-alang, sebagai berikut:

"Tanaman gamal ini pak mampu mematikan alang-alang makanya namanya gamal yang berarti ganyang mati alang-alang, selain itu juga memiliki nilai ekonomis karena dapat dijual untuk kayu bakar tuak (sofi) dan difungsikan sebagai tanaman pagar".

Stepanus (56 tahun, Kepala Desa Gunung).

Tingkat kekritisan lahan menentukan pola penanaman gamal sesuai dengan sistem silvikulur dan volume kayu gamal yang akan dihasilkan. Pada lahan sangat kritis pola 
penanaman memakai jarak tanam 1 x 1 meter dengan volume gamal sebanyak 10.000 pohon/ha, hal ini dimungkinkan karena pada lahan sangat kritis hanya jenis tanaman pionir yang dapat tumbuh. Sedangkan pada lahan kritis, agak kritis gamal berfungsi sebagai tanaman sela diantara tanaman pokok lainnya. Pada lahan potensial kritis gamal berfungsi sebagai tanaman pagar. Potensi Produksi Energi Gamal sebagai Bahan Baku PLTBm Gamal (Gliricidia sepium) adalah nama jenis perdu dari kerabat polongpolongan (suku Fabaceae atau Leguminosae) riap tumbuh 11,5 m3/hektar/tahun. Tanaman Gamal (Gliricidia sepium) dapat mencapai riap $25 \mathrm{~m}^{3} /$ ha/tahun pada $\mathrm{pH}$ tanah $<6$ (Ahmad 2016). Riap yang dipakai dalam memprediksi potensi gamal di lokasi kajian menggunakan riap $11,5 \mathrm{~m} 3 / \mathrm{ha} / \mathrm{th}$ dengan hasil analisis potensi sebesar $98.182 \mathrm{~m} 3 /$ th sebagaimana disajikan pada Tabel 4.

Tabel 4. Potensi kayu Gamal pada lahan kritis

\begin{tabular}{lrrrrr}
\hline \multirow{2}{*}{ Kecamatan } & \multicolumn{2}{c}{ Bahan baku energi pada masing-masing tingkat kekritisan lahan (m3/ha) } & \multirow{2}{*}{$\begin{array}{c}\text { Total } \\
(\mathrm{m} 3) / \text { th }\end{array}$} \\
\cline { 2 - 4 } Borong & Sangat Kritis & \multicolumn{1}{c}{ Kritis } & Agak Kritis & Potensial Kritis & 8.159 \\
Rana Mese & 648 & 5.128 & 1.765 & 125 & 125 \\
Kota Komba & - & - & - & 9 & 7.591 \\
Elar & 1.020 & 6.504 & 58 & 149 & 2.021 \\
Elar Selatan & 156 & 1.236 & 480 & 202 & 7.619 \\
Sambi Rampas. & - & 1.676 & 3.741 & 2.417 & 28.526 \\
Poco Ranaka & 2.744 & 20.052 & 1.373 & 74 & 13.018 \\
Poco Ranaka Timur & - & 11.571 & 895 & 5 & 17.059 \\
Lamba Leda & 3.109 & 13.050 & - & 678 & 14.065 \\
\hline \multicolumn{1}{c}{ Total } & 1.501 & 11.885 & 13.624 & 4.277 & 98.182 \\
\hline
\end{tabular}

Sumber: Diolah dari data primer (2017)

Volume kayu Gamal sebesar 98.181,76 $\mathrm{m}^{3}$ dapat membangkitkan energi listrik sebesar 18,90 MW dengan perhitungan nilai kalor yang digunakan sebesar 4,9 Kkal (Elevitch dan Francis 2006). Rincian potensi energi listrik sebagaimana disajikan pada Tabel 5.

Tabel 5. Potensi energi listrik untuk PLTBm

\begin{tabular}{|c|c|c|c|c|c|}
\hline \multirow{2}{*}{ Kecamatan } & \multicolumn{4}{|c|}{$\begin{array}{l}\text { Potensi Energi pada masing-masing tingkat kekritisan lahan } \\
(\mathrm{MW} / \mathrm{th})\end{array}$} & \multirow[b]{2}{*}{$\begin{array}{r}\text { Total } \\
(\mathrm{MW} / \mathrm{th})\end{array}$} \\
\hline & Sangat Kritis & Kritis & Agak Kritis & Potensial Kritis & \\
\hline Borong & 0,13 & 1,00 & 0,35 & 0,12 & 1,60 \\
\hline Rana Mese & - & - & - & 0,02 & 0,02 \\
\hline Kota Komba & 0,20 & 1,27 & 0,01 & 0,00 & 1,49 \\
\hline Elar & 0,03 & 0,24 & 0,09 & 0,03 & 0,40 \\
\hline Elar Selatan & - & 0,33 & 1,12 & 0,04 & 1,49 \\
\hline Sambi Rampas. & 0,54 & 3,93 & 0,65 & 0,47 & 5,59 \\
\hline Poco Ranaka & - & 2,27 & 0,27 & 0,01 & 2,55 \\
\hline Poco Ranaka Timur & 0,61 & 2,56 & 0,18 & 0,00 & 3,34 \\
\hline Lamba Leda & 0,29 & 2,33 & - & 0,13 & 2,42 \\
\hline Total & 1,80 & 13,93 & 2,67 & 0,84 & 18,90 \\
\hline
\end{tabular}

Sumber: Diolah dari data primer (2017) 
Berdasarkan tabel di atas, pemenuhan kebutuhan bahan baku PLTBm sebesar 10 MW dapat terpenuhi. Potensi terbesar terdapat di Kecamatan Sambi Rampas yang memiliki luas lahan sebesar 65.983 ha dan berpotensi membangkitkan energi listrik sebesar 5,59 MW. Sedangkan, Kota Komba yang merupakan lokasi PLTBm memiliki potensi energi listrik yang dihasilkan sebesar 1,49 MW. Berdasarkan kriteria tingkat kekritisan lahan potensi terbesar terdapat pada lahan kritis sebesar 13,93 MW tersebar pada 8 Kecamatan dimana diperlukan diperhitungkan jarak angkut bahan baku dari lokasi ke pembangkit. Kecamatan Poco Ranaka dengan jarak ke lokasi pembangkit \pm 70 $\mathrm{Km}$ pengangkutan bahan baku berupa chips lebih efisien dan efektif, sedangkan untuk lokasi di Kecamatan Kota Komba bahan baku dapat berupa batang.

Pembangunan PLTBm bahan baku Gamal (Gliricidia sepium) sesuai dengan tujuan pemerintah melalui Peraturan Menteri Energi dan Sumberdaya Mineral Nomor 38 Tahun 2016 dan akan terbangun masyarakat mandiri energi dan mandiri ekonomi. Selama ini, Gamal masih dipergunakan oleh masyarakat sebagai kayu bakar dan dijual pada industri minuman khas pulau Flores (Tuak/Sofi) dengan kisaran harga Rp. 5000/2 $\mathrm{m}^{3}$, menurut Cahyono (2008) harga jual kayu sebagai bahan baku substitusi batubara Rp. 300.000/ton.

Gamal (Gliricidia sepium) memberikan dampak terhadap kesuburan tanah dimana berdasarkan hasil penelitian Chirwa at all (2006) kandungan Nitrogen $96 \mathrm{~kg} / \mathrm{ha}$. Bahan organik di bawah tegakan Gamal (Gliricidia sepium) sebesar 3,56\%, biomassa karbon pada daun sebesar 30,65 ton/ha, pada batang basah 13,65 ton/ha produksi hijauan makan ternak sebesar 30 ton/ha (Nulik 2016). Keuntungan penggunaan gamal sebagai pupuk hijau diketahui bermanfaat untuk: meningkatkan bahan organik tanah dan nitrogen, perbaikan karateristik fisik tanah, aerrasi dan drainase, mengurangi erosi permukaan tanah, menurunkan temperatur tanah, dan mengurangi penguapan air tanah

\section{SIMPULAN DAN SARAN}

\section{Simpulan}

1. Lahan kritis yang dapat dikembangkan untuk pembudidayaan tanaman Gamal (Gliricidia sepium) di Kabupaten Manggarai Timur seluas 187.463 hektar. Areal berpotensi tersebut tersebar hampir di seluruh kecamatan kecuali Kecamatan Elar.

2. Potensi biomassa dari pengembangan tanaman Gamal (Gliricidia sepium) untuk membangkitkan listrik sebesar 10 MW dapat tercapai, dimana berdasarkan hasil analisis lahan kritis potensi biomassa Gamal (Gliricidia sepium) sebesar $98.181,76 \mathrm{~m}^{3} /$ tahun dan dapat mensuplai kebutuhan energi pembangkit listrik sebesar 18,90 MW.

\section{Saran}

1. Mengingat sebaran lahan kritis yang berpotensi untuk pengembangan tanaman Gamal (Gliricidia sepium) di tujuh Kecamatan, perlu dikaji lebih lanjut efisiensi biaya dan efektivitas kerja dalam sistem distribusi bahan baku

2. Pola kemitraan dengan masyarakat perlu memperhatikan kultur budaya lokal dan karakter masyarakat yang hidup di lahan kering berbukitan yang keras serta diharapkan pola kemitraan tidak bersifat top-down namun lebih memperhatikan keinginan masyarakat. Pola kemitraan merupakan cara terbaik untuk menghemat biaya. Kegagalan komunikasi dalam pola kemitraan dapat dipastikan menjadi penghambat kinerja dan kegagalan program pengembangan PLTBm di Kabupaten Manggarai Timur.

\section{UCAPAN TERIMA KASIH}

Terima kasih yang sebesar-besarnya kepada Kepala KPH Manggarai Timur 
dan seluruh jajaran dan Direktorat Jenderal Perubahan Iklim KLHK.

\section{DAFTAR PUSTAKA}

Ahmad NR. 2016. Sumber Daya Hutan Untuk Energi Terbarukan. Makalah disampaikan dalam Kongres Kehutanan Indonesia-IV tanggal 29 November - 2 Desember 2016 Hotel Grand Sahid Jaya Jakarta.MAPEBHI.

[BI] Bank Indonesia (2009). Kajian ekonomi regional Provinsi Nusa Tenggara Timur Triwulan II-2012. Kupang.

[BP-PEN] Badan Pengkajian Pengembangan Energi Nasional (2006). Blueprint Pengelolaan energi Nasional 2006-2025. Jakarta, Indonesia.

[BPPT] badan Pengkajian Penerapan Teknologi (2016). Outlook Energi Indonesia 2016. Badan Pengkajian dan Penerapan Teknologi. Jakarta.

Cahyono, T. D., Coto, Z., \& Febrianto, F. (2008). Analisis Nilai Kalor Dan Kelayakan Ekonomis Kayu Sebagai Bahan Bakar. Forum Pascasarjana, 31(2), 105-116.

Chirwa W.P., Black R.C., Ong K.C., Maghembe M. 2006. Nitrogen dynamics in cropping systems in southern Malawi containing Gliricidia sepium, pigeonpea and maize. Agroforestry Systems (2006) 67:93-106.

[DESDM DEpartemen Esenrgi dan Sumber Daya Mineral (2006). Peraturan Menteri Energi dan Sumber Daya Mineral Nomor 48212/40/600.2/2006 tentang Penetapan Kondisi Krisis Penyediaan Tenaga Listrik, Jakarta. Indonesia.

Elevitch, Craig R. Francis, J. K. (2005). Gliricidia sepium. Traditional Tree Iniciative, 1(Figura 2), 461-471.

[ESDM] Energi Sumber Daya Mineral (2015). Renstra Direktorat Jenderal Ketenagalistrikan 2015-2019. Jakarta, Indonesia.

German, Laura. Ramisch, Joshua J. Verma, R. (2010). Beyond the Biofisical: knowledge, Culture and Power in Agriculture and Natural Resource. (R. German, Laura. Ramisch, Joshua J . Verma, Ed.). Bogor, Indonesia.

Hargiardana, O. (2013). Krisis Listrik dan Program 35 Ribu MW. $M \& E, 13(2), 17-25$.

Lassa, J., Mau, Y. S., Li, D. E., \& Frans, N. (2014). Impact of Climate Change on Agriculture and Food Crops: Options for Climate Smart Agriculture and Local Adaptation in East Nusa Tenggara, Kupang. Indonesia. Newspaper Irgsc (8):2339-06381.

McKendry, P. (2002). Energi production from biomass (part 1): overview of biomass. Bioresource Technol, 83(1), 37-46.

Njurumana, Gerson ND. Victorino, B. P. (2008). Potensi Pengembangan Mamar sebagai Model Hutan Rakyat Dalam Rehabilitasi Lahan Kritis di Timor Barat. Jurnal Penelitian Hutan Dan Konservasi Alam, V.(5): 473-484.

Nulik J., Hau J.K., 2016. Tanaman Gamal (Gliricidia sepium) dan Potensi Pemanfaatannya Sebagai Pakan ternak dan fungsi lainnya dalam usahatani di Nusa Tenggara Timur. Jurnal Balai Pengkajian Teknologi Pertanian (BPTP) NTT.

Pasaribu, S. M. (2007). Revitalizing Institutions To Enhance Climate Forecast Application in East Nusa Tenggara. Analisa Kebijakan Pertanian, 5(3), 239-253.

[Perpres] Peraturan Presiden Republik Indonesia (2017). Rencana Umum energi Nasional dalam Lampiran Peraturan Presiden Republik Indonesia Nomor 22 Tahun 2017, Pub. L. No. 22 Tahun 2017 (2017). Indonesia.

[PLN] Perusahaan Listrik Negara (2016). Statisitik Perusahaan Listrik Negara 2015. Jakarta, Indonesia.

[PLN] Perusahaan Listrik Negara (2017). Statistik Perusahaan Listrik Negara 2016. Jakarta, Indonesia.

Prakoso, A. B. (2014). Design and Optimization of Renewable energi Power Plant in Pengadangan Village Priggasela Sub District east Lombok District NTB. Gadjah Mada University.

Price, B. (1998). Electricity from biomass. London, England: Financial Times Energi.

Roliadi, H. D., \& Anggraini, D. (2010). Eksploitasi Kayu Hutan Tanaman Industri Jenis Eucalyptus Hybrid sebagai Bahan Baku Pupl Kerta. Jurnal Penelitian Hasil Hutan, 28(4), 332-357.

Wolo, Adrianus. Winahju, W. S. (2009). Analisis Kebutuhan Listrik di Wilayah Nusa Tenggara Timur. (newspaper) Jurusan MIPA. Institut Teknologi Surabaya. 